\title{
Schooling opportunities for girls as a stimulus for fertility change in rural Pakistan
}

\author{
Zeba Sathar \\ Population Council \\ Cynthia B. Lloyd \\ Population Council \\ Cem Mete \\ Minhaj ul Haque \\ Population Council
}

Follow this and additional works at: https://knowledgecommons.popcouncil.org/departments_sbsr-pgy

Part of the Demography, Population, and Ecology Commons, Family, Life Course, and Society Commons, Gender Equity in Education Commons, and the International Public Health Commons How does access to this work benefit you? Let us know!

\section{Recommended Citation}

Sathar, Zeba, Cynthia B. Lloyd, Cem Mete, and Minhaj ul Haque. 2000. "Schooling opportunities for girls as a stimulus for fertility change in rural Pakistan," Policy Research Division Working Paper no. 143. New York: Population Council. Version of record: https://doi.org/10.1086/375519 


\section{Schooling 0 pportunities for Girls As a Stimulus for Fertility Change in Rural Pakistan}

Zeba Sathar

Cynthia B. Lloyd

Cem Mete

Minhaj ul Haque

2000 No. 143 


\title{
Schooling Opportunities for Girls As a Stimulus for Fertility Change in Rural Pakistan
}

\author{
Zeba Sathar \\ Cynthia B. Lloyd \\ Cem Mete \\ Minhaj ul Haque
}

Zeba Sathar is Deputy Representative and Program Associate, Population Council, Pakistan. Cynthia B. Lloyd is Director of Social Science Research, Policy Research Division, Population Council, New York. Cem Mete is Population Council postdoctoral fellow at Yale University, New Haven. Minhaj ul Haque is Senior Program Officer, Population Council, Pakistan.

The authors acknowledge the generous support of the Rockefeller Foundation and the helpful comments of Sajeda Amin and T. Paul Schultz. 


\begin{abstract}
This paper tests Caldwell's mass schooling hypothesis in the context of rural Pakistan. His hypothesis was that the onset of the fertility transition is closely linked to the achievement of "mass formal schooling" of boys and girls. Punjab and Northwest Frontier Province (NWFP) were selected for this study because they appear to be on the leading edge of the demographic transition - a transition that has only recently begun - as suggested by rapid recent increases in contraceptive practice. The study covered a range of rural villages or communities with very different socioeconomic and schooling conditions in order to examine the effects of both school access and quality on family-building behavior in Pakistan. The study concludes that gender equity in the schooling environment, as measured by the number of public primary schools for girls in the community or by the ratio of the number of girls' schools to boys' schools, has a statistically significant effect on the probability that a woman will express a desire to stop childbearing and, by extension, on the probability that she will operationalize those desires by practicing contraception. Indeed, the achievement of gender equity in primary school access in rural Punjab and NWFP could lead to a 14-15 percentage point rise in contraceptive use in villages where no girls' public primary school currently exists and an 8 percentage point rise in villages with one primary school for girls. This is entirely supportive of the Caldwell argument that mass schooling is an important determinant of fertility change, particularly when girls are included. It would appear that fertility change will be much more difficult and will come much more slowly when girls are left behind.
\end{abstract}

This material may not be reproduced in any form without written permission from the authors. 
Pakistan is at a critical moment in its social development. While population growth rates remain high, there are signs that parents' family-building strategies, even in rural areas, are beginning to change. Between 1994 and 1997, current contraceptive use rates have increased sharply, from 18 to 24 percent, with rural rates rising from 11 to 19 percent (Hakim, Cleland, and Bhatti 1998). Contraceptive prevalence did not begin to increase in rural areas until the 1990s and therefore has not yet had a noticeable impact on fertility (Sathar and Casterline 1998). Within this context of overall change lies tremendous variation, with some rural communities in the vanguard of change while others remain relatively untouched.

In a review of the demographic situation in Pakistan, Sathar and Casterline (1998) attribute the beginnings of a marital fertility transition to a "crystallization of existing desires for smaller families, along with a decline in family size desires and a reduction in the social, cultural, and psychic costs of contraception" (p. 898). Estimates of national fertility rates suggest a gentle decline from 6.0 births per woman in 1992 to 5.6 in 1995. Urban fertility decline started earlier and has exceeded change in rural areas. Recent estimates of the total fertility rate in rural areas range from 5.7 to 6.3. While this fertility decline, as noted above, has been accompanied by increases in contraceptive use in the 1990s, improvements in family planning services appear to have contributed little to these changes. ${ }^{1}$

Along with the many demand-side factors that are likely to cause couples to reduce their family size desires and to help couples implement them (including economic and social changes leading to a greater demand for girls' schooling) are the supply-side factors associated with changes in the service-delivery environment for family planning, health, and schooling services. The schooling environment in the community, particularly schooling for girls, is the focus of this paper. All indicators show some improvement in the education sector in recent years in 
Pakistan (Khan, Kazmi, and Latif 1999; UNESCO 1999; Sathar, Lloyd, and ul Haque 2000). Steady, slow improvements in overall primary school enrollment ratios in the 1980s have been followed by contradictory trends for girls and boys. From 1991 to 1996/97, primary school enrollment rates for girls have continued to rise in both rural and urban areas, while boys' enrollment rates have declined in both areas (Federal Bureau of Statistics 1997).

This paper explores many of the possible factors explaining the diversity of family-building experiences prevalent in rural Pakistan, using primary data collected specifically for this purpose in rural Punjab and Northwest Frontier Province (NWFP). Punjab and NWFP were selected for this study because each exhibits enormous demographic diversity. Furthermore, both provinces appear to be on the leading edge of the demographic transition in Pakistan, if measured on the basis of recent rapid increases in contraceptive practice. Among provinces in Pakistan Punjab has the highest contraceptive prevalence levels, and NWFP experienced the most rapid rise in contraceptive use in the early 1990s. Our goal was to visit a range of rural villages or communities that reflect significantly diverse socioeconomic and schooling conditions in order to explore the possible links between the schooling environment at the community level and familybuilding patterns.

In particular, we emphasize the status of primary schooling in the community as a factor of policy significance. Caldwell (1980) hypothesized that the onset of the fertility transition would be linked to the achievement of "mass formal schooling" or near universal enrollment of children in primary or basic education. Furthermore, he hypothesized that mass schooling was unlikely to lead to fertility decline in situations where mass schooling is restricted to boys. Caldwell's hypothesis was largely framed at the national level in terms of state policies enforcing compulsory schooling laws, but it can be equally well applied at the subnational level where policies that affect the establishment of schools and their 
resources are determined. ${ }^{2}$ It is especially germane in highlighting the importance of improving the school environment for girls.

This paper begins with a discussion of Caldwell's (1980) work as well as the earlier work of Becker and Lewis (1973) as adapted to the Pakistani context. This is followed by a brief review of the empirical literature on modeling the determinants of family planning practice, our indicator of family-building strategies. The next section introduces our data, which include descriptive evidence of the demographic and economic diversity characteristic of rural Pakistan. The final section presents the results of our multivariate analysis, starting with a discussion of our modeling strategy and ending with simulations of the relationship between various aspects of the community infrastructure, including the availability and quality of public schools for boys and girls, the availability of a family planning clinic, and the level of family planning practice.

\section{SCHOOLING OPPORTUNITIES AS A FACTOR IN DECLINING FAMILY SIZE DESIRES}

It has been some two decades since the publication of Caldwell's (1980) article on mass schooling. In it, he hypothesized that the enforcement of compulsory schooling laws by the state would change the economics of the family, leading to fertility decline even among uneducated parents as the economic value of children was reduced while their costs rose. At that time, he faulted much of the literature on education and fertility in developing countries for having neglected the impact of children's schooling on the reproductive decisionmaking of parents, concentrating instead on the impact of parents' own education on their subsequent fertility. Although the period since Caldwell's article has encompassed the start of many fertility declines throughout the world, the same criticism could be even more aptly leveled at the literature today. In a review of the state of knowledge on the relationship between education and fertility by the Committee 
on Population of the National Academy of Sciences (Bledsoe et al. 1999), not a single article addresses this aspect of the relationship.

When adapted to the subnational level, Caldwell's hypothesis is entirely consistent with predictions by Becker and Lewis (1973) and Becker (1991) of rapid fertility decline in response to rises in the price of children, as parents trade off quantity (or number of children) for quality (or investments in children). Becker and Lewis's model contains an underlying assumption that parents invest equally in all children and that, when investments in quality go up, they are distributed equitably. On this assumption, a decrease in the price of quality (through greater access to school) leads to an increase in the demand for quality, thus increasing the price of a given number of children. This rise in the price of quantity leads to a decline in the demand for quantity relative to quality, thus linking quantity and quality in a very tight tradeoff loop. "A basic insight of these models is that the shadow prices of child quantity and child quality are inextricably linked" (Lam and Duryea 1999, p. 163). The implication of this link is that a decline in the price of quality or a rise in the price of quantity can lead to relatively large declines in fertility.

However, in settings where parents invest in varying amounts of quality for their children according to sex, birth order, or natural endowments, these tight theoretical links become looser. Girls and boys are not exact substitutes, being valued by parents for different reasons. A "high-quality" girl may be different from a "high-quality" boy and may require different inputs. Nonetheless, a decline in the price of one aspect of quality for girls (in this case schooling, in terms of both access and quality) should help equalize parents' investments in schooling between boys and girls, increasing the cost of an additional child regardless of whether it is a boy or a girl. This is clearly the reason why Caldwell doubted whether the arrival of mass schooling could have the same impact in triggering the onset of the fertility transition if it did not also include girls. 
Increases in the supply of public primary schools for girls have been a relatively new phenomenon in Pakistan, resulting from donor pressure and changes in government policy as reflected most recently in the Social Action Program (SAP), which began in $1993 .{ }^{3}$ This program is intended to redress the neglect of the social sectors, particularly by targeting primary school enrollment and expansion in the supply of girls' schools. A change in the community schooling environment for girls resulting from the establishment of a public girls' school where previously there were only public schools for boys should be concomitant with wider investment opportunities for parents. Theoretically it should have an immediate impact on the price of quality for girls, leading parents toward greater equalization of their investments in boys and girls. The expected outcome should be a change in family-building strategies typically manifested initially through a change in expressed fertility intentions and then through a rise in contraceptive use as couples begin to limit their fertility.

We hypothesize that the accessibility and quality of primary schools in the community, in particular the quality and accessibility of all public girls' primary schools, will have a positive effect on the motivation to stop childbearing, controlling for other relevant factors, and the desire to have fewer children will in turn result in higher contraceptive use rates. We base this hypothesis both on theory and on our knowledge and understanding of the current situation of primary schooling in Pakistan. The extent to which the availability of public allgirls schools can be considered exogenous is obviously important for the validity of our findings. Our own data on the history of the establishment of public schools in each community suggest that recent demand for new schools is primarily being expressed in communities that were historically underserved. Indeed, it appears that many of these underserved communities have mobilized and submitted petitions to district authorities for the establishment of public primary schools. In some cases, schools have been established after the filing of such petitions, 
while in other cases such requests have been denied. However, it is very difficult to determine cause and effect in these cases. Indeed, in the last five years the predominant trend has been the growth of private schools, which suggests that growing demand is not being met by the public sector. From 1992 to 1997 ten new private schools and three new public schools were established in these communities, only two of which were for girls. The result has been the creation of additional and much more expensive choices for parents in some communities. However, parents express strong preferences for single-sex primary education for both boys and girls, and these newer private schools do not respond to these deeply held preferences as they are all either mixed or for boys only. ${ }^{4}$

Improvements in access to girls' schools and an increase in their quality will increase parents' desires for higher-quality girls, thus narrowing the gap between the desires for girls and boys of high quality. Particularly because the bearing of at least two sons is believed to be a major motivation for Pakistani parents to continue childbearing, a rising desire for high-quality girls will increase the costs associated with such gender-specific fertility goals and should lead to a reduction in overall fertility desires. The result should be an increasing desire by parents to stop childbearing after having two or more living children, with a diminution in gender preference for children. In sum, we would expect an increased motivation to adopt the use of family planning methods in communities where there is greater gender equity in access to and quality of primary schooling.

\section{THE COMMUNITY DETERMINANTS OF CONTRACEPTIVE USE}

Most researchers studying the community determinants of contraceptive use have been motivated by the goal of isolating statistically the role of family planning services as a factor explaining contraceptive use (and often the choice of methods), while controlling for other individual, household, and community determinants. In addition, they have often measured those aspects of family plan- 
ning services that matter the most in a given setting. While information on the schooling environment is occasionally included as one aspect of the community environment, it is rarely given a special focus in these analyses.

Empirical results usually confirm the statistical importance of particular features (which vary from country to country depending on the design of the program) of the family planning program at the community level for contraceptive use. Typically, these are direct effects that change the costs of contraception rather than indirect effects that modify fertility desires. For example, in the Philippines, DeGraff, Bilsborrow, and Guilkey (1997) found that the presence of a family planning worker in the village had a statistically significant effect on contraceptive use. Gertler and Molyneaux (1994) found that family planning team visits and the presence of health clinics had a significant positive effect on contraceptive use in Indonesia. Both of these studies also included other community variables capturing the presence of various types of infrastructure and certain proxies for labor market opportunities whose effects on contraceptive use worked primarily through their effects on fertility desires.

The statistical methodologies employed in recent empirical studies of the role of community factors as determinants of contraceptive use in developing countries have become increasingly sophisticated: (1) estimating equations (or systems of equations) with discrete dependent variables; (2) operating with less restrictive assumptions on the distribution of error terms; and (3) estimating structural models that provide a more realistic representation of the sequential decisionmaking process. ${ }^{5}$ Through the development of multiple equation systems to estimate structural models, these studies have identified the pathways through which community factors operate, whether indirectly or directly.

While recent studies have included countries at various phases of the demographic transition (e.g., Indonesia, Malawi, the Philippines, Thailand, Tunisia, and Zimbabwe), few have distinguished in their models between the deter- 
minants of contraceptive use as motivated by the desire to space births and the determinants as motivated by the desire to limit births (see Guilkey and Jayne 1997 as a notable exception). Instead most have focused on the community factors affecting overall levels of use and the choice of specific methods, even though some of these methods may be adopted by both spacers and limiters. Recent examples include studies carried out by DeGraff, Bilsborrow, and Guilkey (1997) in the Philippines; Cochrane and Guilkey (1995) in Tunisia; and Entwistle et al. (1996) in Thailand. This approach makes sense when the effects of various features of family planning programs on contraceptive use are being tested, because one would expect that the quality and accessibility of the programs would affect the costs of contraceptive use for both spacers and limiters. However, when attention shifts to the role of schools in the community, one would expect that the primary pathway of influence would be through the effect of schooling opportunities on the motivation to limit fertility, with relatively little effect on the motivation to space. By mixing spacers and limiters in the same analysis, the potential role of schooling conditions may be less precisely estimated.

We have been able to identify only a few studies that have explored the empirical relationship between children's schooling opportunities at the district, community, or state level and cross-sectional variations in fertility desires, fertility behavior, or contraceptive use. The most common approach has been to use distance to the nearest school as a measure of access. However, this approach, when applied in separate studies in Bangladesh, Pakistan, Syria, and Thailand (as summarized in Casterline 1987), produced no empirical links between school access and fertility aspirations. The World Fertility Survey (WFS) data on which these studies relied were based on the subjective reports of community informants rather than on independent observation of the actual distance.

When primary school enrollment rates at the community or state levels have been used to capture a fuller measure of schooling opportunities, stronger 
empirical links with actual contraceptive use have been found. In the case of Egypt, Casterline (1985) found, using rural data from the 1980 WFS survey, that current contraceptive use was affected positively by the village primary school enrollment rate for girls but negatively by the primary school enrollment rate for boys. In a cross-state comparison of 23 sub-Saharan African countries, Lloyd, Kaufman, and Hewett (2000) found a strong empirical link between the achievement of mass schooling and the onset of the fertility transition. This was established by using a Spline regression technique that allowed the estimated relationship between grade-four attainment rates and alternative measures of fertility decline to take a different slope before and after the achievement of mass schooling (defined by the authors as the point at which 75 percent or more of 15-19year-olds have completed at least four years of schooling). While these results are suggestive, they cannot be interpreted as causal because enrollment rates, which in both studies were used as the "independent variable," reflect not only schooling opportunities but also the strength of demand for schooling.

More recently a few studies give hints about the potential effects of schooling availability in the community on family-building behavior when that availability is captured using independently collected data at the community level. By analyzing data from the 1989 Zimbabwe DHS as part of a comprehensive analysis of individual, familial, and community determinants of contraceptive use and method choice, Guilkey and Jayne (1997) showed that the number of educational opportunities in the community (a variable used in the multivariate analysis whose measurement was not clearly defined) had a positive and statistically significant effect on contraceptive use. In an even more ambitious analysis of the role of economic development and family planning programs in the Indonesian fertility decline, Gertler and Molyneaux (1994) include, without comment, the number of primary schools per 1,000 population and the number of junior high schools per 1,000 population in a weighted, fixed-effects, structural proximate determinants 
model. Controlling for the supply of primary schools, an increased number of junior high schools is estimated to increase significantly the use of contraception while, controlling for the supply of junior high schools, an increased number of primary schools is estimated to decrease significantly, but by a much smaller amount, the level of contraceptive use. In Indonesia, a country where 84 percent of 15-19-year-olds have completed primary school or higher (Gardner 1998), it would appear that an increased supply of junior high school places in the community has a positive effect on contraceptive use.

Most recently, Axinn and Barber (1999), using rich contemporary and retrospective data on 171 communities in Nepal, found that living near a school significantly increases a woman's chance of adopting a permanent contraceptive method, even after controlling for the proximity of a school during a woman's childhood—a variable with its own independent effect on contraceptive use. ${ }^{6}$ This study, which is based on data that were specially designed and collected to test such a hypothesis, is the only one of those reviewed to directly test Caldwell's mass-schooling hypothesis, and it provides clear confirmation of its relevance in the context of Nepal.

\section{DATA}

This study was undertaken in December 1997 in 12 rural communities in Pakistan — six in Punjab and six in Northwest Frontier Province-drawn from three districts in each province; follow-up visits were made to schools in the communities in mid-1998 and again in mid-1999 during the regular school term. In order to sample the diversity in schooling conditions within rural Punjab and NWFP, district schooling and income data from the 1995/96 Pakistan Integrated Household Survey (PIHS) were used to aid in identifying districts and ultimately villages or primary sampling units (PSUs) that were eligible for inclusion in the study. 
Because variations across districts in enrollment rates can be explained by both demand- and supply-side conditions, we wanted to identify a set of potentially eligible districts whose schooling rates were not entirely explained by levels of income; our hope was to capture variations in schooling at the community level that could reflect variations of supply conditions that might be independent of demand conditions. To make this selection, we ran a simple linear regression across districts within each province (using data from the 1995/96 PIHS) between the proportion of children aged 7-14 currently enrolled in school and per capita consumption, in order to estimate the statistical relationship between per capita income and enrollment. ${ }^{7}$ From this regression, we identified those districts, from among those with relatively high enrollment rates in the province, that had enrollment rates higher than those predicted by the regression line; those districts, from among those with average enrollment rates, that fell close to the regression line; and those districts, from among those with relatively low enrollment rates in the province, that had enrollment rates lower than those predicted by the regression line.

From this regression analysis, Sialkot and Abottabad districts were selected at random from the list of potentially eligible districts as representing those with higher-than-expected enrollment, D.G. Khan and Karak as the middle-achieving districts, and R.Y. Khan and Swat as those with lower-than-expected enrollment in Punjab and NWFP, respectively. Within each of the districts, communities or PSUs were selected at random from among those that had enrollment rates that appeared roughly average for the district selected, as calculated from the PIHS. ${ }^{8}$ Because estimates of enrollment rates at the PSU level were based on very small samples, our actual selections within each district showed a wider variation in enrollment rates than expected from the PIHS data. From our point of view, however, this provided greater variation in schooling conditions in our final sample of 12 PSUs. While we recognize that this purposive sampling strat- 
egy cannot be assumed to have yielded a range of community schooling conditions that can be seen as entirely supply driven, we hope that it has assured us of a sufficient range of conditions to explore the determinants of family building in the context of variations in the supply of schooling at the community level.

Within each PSU, a sample of 50-60 currently married women aged 2045 were interviewed, as were all husbands who could be located during the period the teams were in the villages. The final sample consisted of 722 women and 438 husbands (61 percent) who were found at home and were successfully interviewed; these were roughly evenly divided between Punjab and NWFP. The women were asked to provide basic background information about themselves and their husbands; a full birth and education history for each child; and information on contraceptive knowledge and use, on economic activity, and on attitudes and aspirations about children's schooling. Women's husbands were asked to provide similar background information about themselves and their wives, a somewhat modified birth and education history for each of their children, information about their attitudes and aspirations regarding schooling, and a modified module on income and consumption for the household developed in collaboration with the PIHS. ${ }^{9}$ When a husband could not be interviewed, his wife was asked to complete the schedule on household consumption.

These data were supplemented by an inventory and assessment of most of the primary schools in the communities attended by children in the sample and a profile of other relevant features of the community. Primary schools to be included in the inventory were identified as those that were attended by children in the sample, not just those that were technically within the sample community. ${ }^{10}$ Only in cases where the school was located quite far from the community or attended by fewer than five children in the community was the school left out of the schooling survey. As a result, 82 percent of children currently attending primary school in the sample were attending one of the schools visited. 
Of those whose schools were not visited, 30 percent did not remember the name of the school and the rest named schools that had no more than a few students enrolled from our sample. We feel reasonably confident that our sample of schools reflects the range of school choice in the community. Data collected on schools include information on the number of schools in the community, their type (public, private, boys', girls'), the year they were founded, enrollment, numbers of teachers and their credentials and attendance, as well as various aspects of the physical facilities and of the medium of instruction. These visits were unannounced; we can assume, therefore, that the data collected reflect a typical school day.

Data on schools were collected in three phases. During the first phase, school data were collected concurrently with the fieldwork (December 1997). A second phase in May 1998 collected data from schools missed in the first phase. Finally, in May 1999 the third phase was carried out. At that time information on the history of school formation in each community was collected. The gathering of this information was prompted by our interest in whether school access primarily reflected community demand for schools or whether recent policy initiatives were responsible for the setting up of new schools. Also, five schools that were not originally expected to meet the study criteria were located during analysis of the household data and visited.

In addition to the school inventory, field team leaders filled out a community questionnaire for each of the 12 sample PSUs in consultation with local key informants. This inventory collected data on other important community inputs, including various aspects of the local infrastructure and information on family planning and health service availability.

\section{THE COMMUNITY ENVIRONMENT}

Our sampling strategy was designed to reflect diversity in demographic and economic conditions within Punjab and NWFP. Our data demonstrate that 
the 12 communities are in fact quite different in terms of their schooling and developmental conditions and reproductive behavior. We introduce our data by showing some of the ways that these conditions differ across the 12 communities. The discussion is organized around the variables chosen for our multivariate analysis.

Because our multivariate analysis focuses on the determinants of the desire to stop childbearing as well as the determinants of contraceptive use for those who indicate a desire to stop childbearing, we start by exploring the extent to which our villages vary with respect to these outcome variables (see Table 1). The percentage of currently married women who want no more children varies from 27 percent to 65 percent across the six sample communities in Punjab but is consistently high in the six sample villages in NWFP, ranging from 64 percent to 73 percent. ${ }^{11}$ Current contraceptive use, including both modern and traditional methods, ranges much more substantially in both provinces, from 2 percent to 33 percent in Punjab and from 13 percent to 50 percent in NWFP.

\section{Schooling Opportunities in the Community}

In total, our school sample consisted of 50 nonreligious primary schools. Of these, 36 were public government schools, all of which were officially singlesex. The rest were private schools, many of which were founded relatively recently and all but two of which were mixed. ${ }^{12}$ Of the 36 public schools, 23 were boys' schools and 13 were girls' schools.

Because many parents want to send their children to a nearby school together with their siblings, some single-sex schools are de facto mixed. This practice has also probably come about because, until recently, many communities lacked a girls' school. Nine of the 25 boys' schools in our sample have girls in attendance in grades 1-5, and four of the 13 girls' schools have boys in attendance. However, enrollment of the opposite sex in public single-sex schools tends 


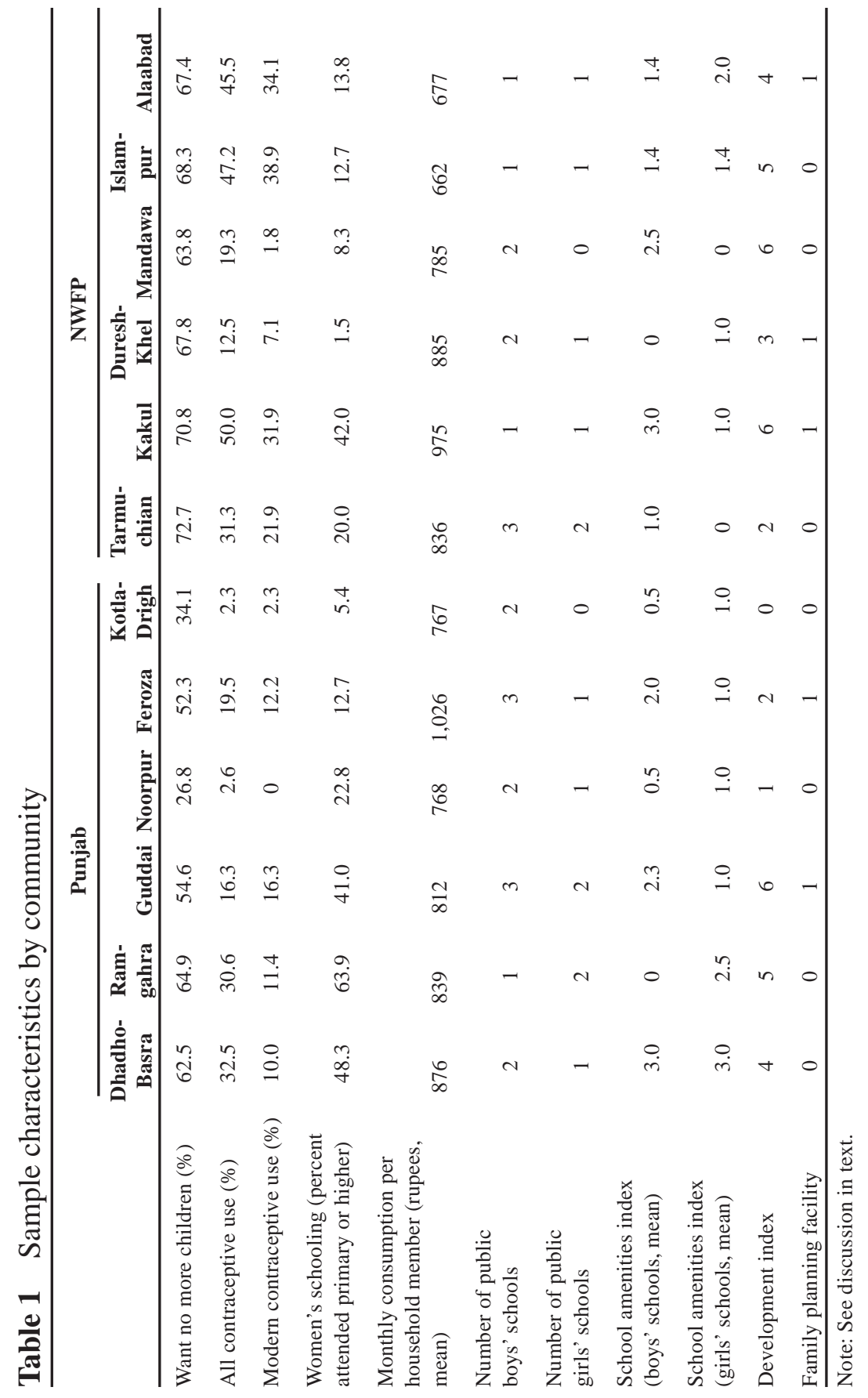


to be small, and attendance rates among this small group, particularly in the case of girls, are low (Sathar, Lloyd, and ul Haque 2000). Furthermore, the few children of the opposite sex who attend these single-sex public schools seem to be concentrated in the preprimary grades, suggesting that it may be convenient for siblings of both sexes, particularly when young, to attend school together. For these reasons, it seemed appropriate for us to consider only public all-girls schools when assessing the accessibility of public schooling for girls and only public all-boys schools when assessing the accessibility of public schooling for boys.

Data on variations across our 12 communities in the number of boys' and girls' public schools within the PSU are presented in Table 1. For boys, the number of schools varies from one to three. On the other hand, the number of public schools available for girls within these same communities varied from zero to two. If we assume that the number of boys' schools is roughly in line with local requirements, we can see that in eight of the 12 communities the ratio of girls' to boys' schools is less than one, implying that the supply of girls' schools is insufficient to allow equity in educational opportunities for boys and girls. All the communities where the ratio of girls' to boys' schools falls below one have at least two schools for boys.

School quality is also highly variable across communities and can be compared between girls' and boys' public schools. One of the indicators of school quality that were developed for this study was an index of the presence of various amenities in each school. We create an amenities index with a range of $0-4$ that awards one point for the presence in the school of each of the following amenities: drinking water, any kind of toilet, electricity, and at least some chairs and desks for the students. These are assessed separately for boys' and girls' schools and are averaged across schools in the community where there is more than one school. Scores for both boys' and girls' schools range from 0 to 3 across the 12 
communities, so there is no school where all amenities are present. In five communities the average amenities index for girls falls below that for boys, in two they are equal, and in five the amenities index is higher for girls than it is for boys. The median value for the average amenities index for boys' schools across communities is slightly higher than that for girls' schools (1.4 vs. 1) but both values are extremely low.

\section{Other Community Characteristics}

Levels of infrastructure within each community were assessed through a combined development index that awarded 1 point for the presence of each of seven elements within the sample PSU: (1) a paved road; (2) public transport within the PSU; (3) sewerage; (4) electricity; (5) telephone; (6) natural gas; and (7) paved streets. No community had all seven elements. Scores ranged from 0 to 6 with 4 as the median. Generally the communities in NWFP had better infrastructure than those in Punjab.

Seven of the 12 communities had no family planning services of any kind despite the fact that a wide range of possible sources of supply was investigated. These included the presence of a lady health worker, a lady health visitor, a village-based family planning worker, and a family welfare center.

Finally, the percentage of women ever attending school ranges from 1.5 percent to 63.9 percent across the 12 villages. Monthly consumption per household member is lowest in Islampur (662 rupees) and highest in Feroza (1,026 rupees).

\section{EMPIRICAL ANALYSIS}

While structural models have the potential to display a more comprehensive set of relationships, in our case a reduced-form approach is preferable mainly because the specific hypothesis that we attempt to verify does not re- 
quire a more elaborate characterization of contraceptive use behavior. In fact, the relationship between school availability/quality and contraceptive use patterns can arguably be most easily and accurately displayed by adopting a basic reduced-form model, which is, to a large extent, isolated from complex model specification and identification assumptions that are required for formulating estimable structural models.

Modeling of contraceptive use behavior is further complicated by the fact that it involves factors that might affect motivations to space as well as motivations to limit childbearing. Furthermore in Pakistan, where the use of traditional methods has been identified as an important contributor to the onset of the fertility decline, we would not necessarily expect the factors affecting the use of modern methods to be entirely the same as those affecting the use of traditional methods (including rhythm and withdrawal).

These considerations can be incorporated into a multilevel approach where, on the first level of analysis, the distinction is made between "want another child now," "want another child later," and "want no more children," and, on the second level, those who want to delay or limit fertility decide between using modern contraceptive methods, using traditional contraceptive methods, and not using contraceptives. Depending on assumptions on the error terms, such a tree structure can be estimated by familiar discrete choice models such as multinomial logit, nested multinomial logit, or multinomial probit.

We started with such an approach using multinomial logit to model the first level of analysis described above and found no statistical difference between women who say they want to delay their next birth and those who say they want another child right away. None of the independent variables chosen for the analysis, some of which were significant in explaining the likelihood of wanting no more children relative to wanting another child right away, had a significant effect on the likelihood of expressing a desire to space relative to the likelihood of 
expressing a desire to have another child immediately. This may be partially due to the small numbers falling into these two groups. Of the 656 currently married women in the sample used in the analysis, 148 ( 23 percent) indicated a desire to have another child right away, 131 (20 percent) indicated a desire to space, and 377 (57 percent) indicated a desire to stop childbearing.

From this first step, we concluded that a simpler approach is warranted in our case. In analyzing fertility preferences, this paper emphasizes factors that would lead to a decline in fertility in Pakistan, so the key issue is distinguishing between those women who do not want another child and those who want more children either now or later. In other words, we combine the categories "want another child now" and "want another child later." Contraceptive use rates are substantially higher for women who want to stop childbearing relative to those who want to space: the contraceptive use rate for those who express a desire for stopping is 34.6 percent, while the rate for those who want to space is 17.9 percent. When one focuses on modern contraceptive use only, the relevant percentages are 20.8 and 10.5 for the two groups. Our analysis of contraceptive use focuses not only on "all contraceptive use"; it also investigates the determinants of the use of modern contraceptives.

The following section focuses on the desire to have no additional children. Then, we model contraceptive use for women who desire to stop childbearing. Finally, we investigate the effect of selected explanatory variables on fertility desires and contraceptive use.

\section{Determinants of the Desire to Stop Childbearing}

The first step in our analysis is to test the hypothesis that access to and the quality of primary schooling in the community have positive effects on women's desire to stop childbearing. ${ }^{13}$ The desire to stop further childbearing is hypoth-

esized to be a function of the characteristics of the woman (age, age squared, 
schooling) and of the household (consumption per household member, whether the couple has two or more living sons), schooling opportunities in the village (captured in two alternative ways: number of boys' and girls' schools in the village, and the ratio of the number of girls' schools to the number of boys' schools), the quality of schools (school amenities index, tabulated separately for girls' and boys' schools), and other community characteristics (development index). The dependent variable takes a value of 1 if the woman does not want any additional children and a value of 0 otherwise.

The characteristics of the samples used according to the variables chosen for the analysis are presented in Table 2. Explanations for the construction of various community variables are provided in the previous discussion of the community environment. Probit regression estimates are reported in Table 3.

At the individual and household level, two variables are statistically significant in explaining variations among women in the desire to stop childbearing - age and the presence of two or more living sons. ${ }^{14}$ While consumption per household member is positively associated with the desire to stop childbearing, the estimated coefficients are not significant at the 10 percent level. Similarly, a dummy variable representing whether or not women had ever attended school is not significant. This finding may seem more surprising, but it is robust to the use of alternative women's schooling variables, such as one that is based on average years in school or one that uses a measure of reading ability (as revealed by the women themselves).

At the community level, we focus first on the role of local primary schooling conditions in the motivation to stop childbearing. While the number of primary schools for boys in the community does not appear to be an important factor, the variable representing schooling opportunities for girls is statistically significant, regardless of whether school opportunities for girls are captured by number of girls' schools in the village, as in Model 1, or as a ratio (number of 
Table 2 Characteristics of the sample used for investigating the desire for additional children

\begin{tabular}{|c|c|c|c|}
\hline Characteristic & Number & & Percent \\
\hline \multicolumn{4}{|l|}{ Age of woman } \\
\hline $20-25$ & 140 & & 23.5 \\
\hline $26-30$ & 161 & & 27.0 \\
\hline $31-35$ & 130 & & 21.8 \\
\hline $36-40$ & 100 & & 16.8 \\
\hline $41-45$ & 66 & & 11.1 \\
\hline \multicolumn{2}{|l|}{$\begin{array}{l}\text { Monthly consumption per household member } / 1,000 \\
\text { (rupees, mean) }\end{array}$} & 0.82 & \\
\hline \multicolumn{4}{|l|}{ Women's schooling } \\
\hline Did not attend primary school & 440 & & 73.7 \\
\hline Attended primary school or higher & 157 & & 26.3 \\
\hline \multicolumn{4}{|l|}{ Number of living sons } \\
\hline Less than two & 229 & & 38.4 \\
\hline Two or more & 368 & & 61.6 \\
\hline \multicolumn{4}{|c|}{ Public boys' primary school access (number inside the village) } \\
\hline 1 & 197 & & 33.0 \\
\hline 2 & 265 & & 44.4 \\
\hline 3 & 135 & & 22.6 \\
\hline \multicolumn{4}{|c|}{ Public girls' primary school access (number inside the village) } \\
\hline 0 & 112 & & 18.8 \\
\hline 1 & 356 & & 59.6 \\
\hline 2 & 129 & & 21.6 \\
\hline \multicolumn{2}{|l|}{$\begin{array}{l}\text { Ratio of number of public girls' schools/ } \\
\text { number of public boys' schools (mean) }\end{array}$} & 0.65 & \\
\hline \multicolumn{2}{|l|}{ School amenities index (public boys' schools, mean) } & 1.50 & \\
\hline \multicolumn{2}{|l|}{ School amenities index (public girls' schools, mean) } & 1.14 & \\
\hline \multicolumn{4}{|l|}{ Development index } \\
\hline $0-2$ & 188 & & 31.5 \\
\hline $3-4$ & 163 & & 27.3 \\
\hline 5-6 & 246 & & 41.2 \\
\hline Total & 597 & & 100 \\
\hline
\end{tabular}

girls' schools/number of boys' schools), as in Model $2 .{ }^{15}$

We have experimented with including in the model various measures of school quality (such as teacher/student ratio; "effective" teacher/student ratio, which takes into account the percentage of teachers in the school at the time of the school visit; teacher experience; and days that school is in session) in addi- 
Table 3 The determinants of wanting no more children

\begin{tabular}{lcc}
\hline Independent variable & Model 1 & Model 2 \\
\hline Age of woman & $0.217^{* *}(2.25)$ & $0.216^{* *}(2.26)$ \\
Age squared & $-0.0022(-1.5)$ & $-0.0022(-1.51)$ \\
Monthly consumption per household member/1,000 & $0.079(0.59)$ & $0.078(0.58)$ \\
Women's schooling dummy & $-0.147(-0.9)$ & $-0.161(-0.99)$ \\
Living sons (1 if two or more living sons, 0 otherwise) & $1.33^{* * *(9.33)}$ & $1.31^{* * *(9.38)}$ \\
Public boys' primary school access (number inside the village) & $-0.09(-0.64)$ & - \\
Public girls' primary school access (number inside the village) & $0.332^{* *}(2.3)$ & - \\
Ratio of number of girls' schools/number of boys' schools & - & $0.404 *(1.8)$ \\
School amenities index (public boys' schools) & $-0.0224(-0.24)$ & $0.00014(0.001)$ \\
School amenities index (public girls' schools) & $0.0187(0.2)$ & $0.009(0.09)$ \\
Development index & $0.118^{* *}(2.3)$ & $0.107^{* *}(2.13)$ \\
Constant & $-5.59 * * *(-3.76)$ & $-5.64 * * *(-3.78)$ \\
Number of cases & 597 & 597 \\
Log-likelihood & -258.32 & -259.65 \\
\hline
\end{tabular}

Note: The numbers in parentheses are t statistics (Huber-White variance estimator is used).

* Significant at $10 \%$ level

** Significant at $5 \%$ level

*** Significant at $1 \%$ level

tion to the basic school amenities indexes that are reported here. School quality does not seem to have a statistically significant influence on fertility behavior, although the estimated coefficients (particularly for measures of the quality of girls' schools) are in the expected direction. The lack of a significant relationship could be partly explained by the gap between parents' perceptions of school quality and the particular way in which quality was measured in our survey. The results of in-depth interviews with parents about the quality of schools in the community suggest that they place much more emphasis on the absenteeism and disciplinary behavior of teachers as well as on the teaching of English (which is perceived to represent better quality by parents but is known by pedagogical experts to be detrimental to learning in the youngest grades) than on other aspects of school quality, such as amenities, class size, or teacher training, that we measured in our study (Sathar, Lloyd, and ul Haque 2000). 
We capture other aspects of the community with a development index. As we would expect, the sign of the coefficient for the development index is positive and significant.

\section{Determinants of Contraceptive Use}

We adopt a probit model with sample selection for estimation (Heckman 1979; van de Ven and van Praag 1981) such that each contraceptive use equation includes a selection correction for the fact that the estimation is based on a selective sample of women (i.e., those who do not want any additional children). ${ }^{16} \mathrm{~A}$ Wald test suggests that the correlation between the error terms of the two equations is not equal to zero, and thus estimating the contraceptive use equation without taking into account the selection process would result in biased parameter estimates. ${ }^{17}$

The explanatory variables for the selection equation are the same as those included in Table 3, Model 1. The explanatory variables for the contraceptive use equation are age, age squared, consumption per household member, a dummy variable for whether or not the woman has ever attended school, development index, and dummy variables to signal whether the husband is away and the presence of a family planning facility inside the village.

The identification of the model is achieved by including the variable "number of living sons" and our measures of school quality and access only in the fertility desires (selection) equation, and including the variables "husband away" and "family planning facility inside the village" only in the contraceptive use equation. Two points are worth elaborating in this specification. First, we hypothesize that primary-schooling opportunities in the community would influence contraceptive use primarily through women's desire to stop childbearing. Second, we hypothesize that the availability of a family planning facility in the village would primarily influence women's contraceptive use (possibly by reducing the costs of contraceptives) rather than their fertility preferences. ${ }^{18}$ 
Table 4 presents descriptive statistics and Table 5 reports the parameter estimates for two alternative models of contraceptive use. Both modern and traditional methods of contraceptive use are considered, and the selection equation distinguishes between women who do not want any additional children and other women. In the second model, contraceptive use is defined to include only modern contraceptives (i.e., women using rhythm, withdrawal, and other traditional methods are considered not to be using modern contraceptives).

Selecting on women who have stated their motivation to stop childbearing, a woman's age and per capita household consumption are not significant factors determining contraceptive use. Whether or not a woman's husband is away temporarily might be expected to influence current use of traditional methods such as withdrawal but not necessarily the use of modern methods. In the equation for all contraceptive use, it does have a negative effect as expected but is not quite statistically significant.

In both models of contraceptive use, women who have ever been to school are significantly more likely to use contraception than those who have never been to school, suggesting that mother's schooling influences contraceptive use primarily by helping women to operationalize their desires rather than by helping them to formulate their desires. This finding demonstrates the payoff to separately considering fertility desires and contraceptive use. Even though the positive association between mother's schooling and contraceptive use has been noted by many researchers (for Pakistan see Sathar et al. 1988; Mahmood 1992; Sathar and Mason 1993; Hakim and Salway 1999), not much is known about the underlying mechanisms that produce the observed contraceptive use patterns.

The presence of a family planning facility inside the village does not have a statistically significant influence on overall contraceptive use behavior but does have a statistically significant positive effect when contraceptive use is confined to modern methods only. This is to be expected, as family planning facilities supply only modern methods. 
Table 4 Characteristics of the samples used for the contraceptive use analysis

\begin{tabular}{|c|c|c|c|c|}
\hline \multirow[b]{2}{*}{ Characteristic } & \multicolumn{2}{|c|}{$\begin{array}{c}\text { Model 1 } \\
\text { (all methods) }\end{array}$} & \multicolumn{2}{|c|}{$\begin{array}{c}\text { Model 2 } \\
\text { (modern methods only) }\end{array}$} \\
\hline & Number & Percent & Number & Percent \\
\hline \multicolumn{5}{|l|}{ Age of woman } \\
\hline $20-25$ & 102 & 21.4 & 102 & 21.5 \\
\hline $26-30$ & 113 & 23.7 & 113 & 23.8 \\
\hline $31-35$ & 110 & 23.1 & 109 & 23.0 \\
\hline $36-40$ & 92 & 19.3 & 91 & 19.2 \\
\hline $41-45$ & 60 & 12.6 & 59 & 12.5 \\
\hline \multicolumn{3}{|l|}{$\begin{array}{l}\text { Monthly consumption per household member/ } \\
1,000 \text { (rupees, mean) }\end{array}$} & \multicolumn{2}{|c|}{0.82} \\
\hline \multicolumn{5}{|l|}{ Women's schooling } \\
\hline Did not attend primary school & 355 & 74.4 & 352 & 74.3 \\
\hline Attended primary school or higher & 122 & 25.6 & 122 & 25.7 \\
\hline \multicolumn{5}{|l|}{ Number of living sons } \\
\hline Less than two & 170 & 35.6 & 170 & 35.9 \\
\hline Two or more & 307 & 64.4 & 304 & 64.1 \\
\hline \multicolumn{5}{|l|}{$\begin{array}{l}\text { Public boys' primary school access } \\
\text { (number inside the village) }\end{array}$} \\
\hline 1 & 157 & 32.9 & 155 & 32.7 \\
\hline 2 & 214 & 44.9 & 213 & 44.9 \\
\hline 3 & 106 & 22.2 & 106 & 22.4 \\
\hline \multicolumn{5}{|l|}{$\begin{array}{l}\text { Public girls' primary school access } \\
\text { (number inside the village) }\end{array}$} \\
\hline 0 & 93 & 19.5 & 92 & 19.4 \\
\hline 1 & 285 & 59.7 & 284 & 59.9 \\
\hline 2 & 99 & 20.8 & 98 & 20.7 \\
\hline \multicolumn{2}{|l|}{ School amenities index (public boys' schools, mean) } & 1.51 & \multicolumn{2}{|c|}{1.51} \\
\hline \multicolumn{2}{|l|}{ School amenities index (public girls' schools, mean) } & & \multicolumn{2}{|c|}{1.12} \\
\hline \multicolumn{5}{|l|}{ Development index } \\
\hline $0-2$ & 146 & 30.6 & 146 & 30.8 \\
\hline $3-4$ & 130 & 27.3 & 130 & 27.4 \\
\hline $5-6$ & 201 & 42.1 & 198 & 41.8 \\
\hline \multicolumn{5}{|l|}{ Husband } \\
\hline Away & 94 & 19.7 & 94 & 19.8 \\
\hline With the interviewed woman & 383 & 80.3 & 380 & 80.2 \\
\hline \multicolumn{5}{|l|}{ Family planning facility } \\
\hline None inside the village & 259 & 54.3 & 257 & 54.2 \\
\hline Inside the village & 218 & 45.7 & 217 & 45.8 \\
\hline Total & 477 & 100 & 474 & 100 \\
\hline
\end{tabular}

Note: The contraceptive use equations in both models use "want no more children" as the dependent variable for the selection equations. 
Table 5 Determinants of contraceptive use

\begin{tabular}{lcc}
\hline Independent variable & $\begin{array}{c}\text { Model 1 } \\
\text { (all methods) }\end{array}$ & $\begin{array}{c}\text { Model 2 } \\
\text { (modern methods only) }\end{array}$ \\
\hline Age & $-0.148(-1.2)$ & $-0.083(-0.6)$ \\
Age squared & $0.002(0.84)$ & $0.0007(0.34)$ \\
Monthly consumption per household member/1,000 & $0.034(0.23)$ & $-0.098(-0.69)$ \\
Women's schooling dummy & $0.512 * * *(3.19)$ & $0.424 * *(2.53)$ \\
Development index & $0.024(0.63)$ & $-0.035(-0.82)$ \\
Husband away & $-0.257(-1.44)$ & $0.145(0.82)$ \\
Family planning facility inside the village & $0.0006(0.005)$ & $0.241 *(1.83)$ \\
Constant & $3.01(1.45)$ & $1.61(0.68)$ \\
Number of cases & 477 & 474 \\
Censored & 191 & 191 \\
Uncensored & 286 & 283 \\
Wald test statistic (for $\rho=0)$ & 31.07 & 19.55 \\
Log-likelihood & -362.72 & -329.2566 \\
\hline
\end{tabular}

Notes: The numbers in parentheses are t statistics (Huber-White variance estimator is used); the explanatory variables in the selection equations (coefficients not reported) are age, age squared, consumption per household member, women's schooling, two or more (living) boys dummy, boys' and girls' primary school availability, boys' and girls' school amenities indexes, and development index.

* Significant at $10 \%$ level

** Significant at $5 \%$ level

*** Significant at $1 \%$ level

\section{Simulations}

Based on the parameter values reported in the first column of Table 5, Table 6 reports predicted probabilities of contraceptive use for women who express a desire to stop childbearing and who have average values on other relevant characteristics according to: (1) a range of values on the number of girls' primary schools in the community; (2) whether or not mothers had ever been to school; (3) the level of infrastructure in the community, as measured by the development index; and (4) whether or not there was a family planning facility inside the village.

In the base scenario where all explanatory variables are at their median values, the estimated probability of any contraceptive use for women who want 
Table 6 Estimated probabilities of contraceptive use based on the models presented in Table 5

\begin{tabular}{lcc}
\hline & $\begin{array}{c}\text { Model 1 } \\
\text { (all methods) }\end{array}$ & $\begin{array}{c}\text { Model 2 } \\
\text { (modern methods only) }\end{array}$ \\
\hline Number of public girls' schools & 0.25 & \\
0 & 0.33 & 0.06 \\
1 & 0.39 & 0.14 \\
2 & & 0.21 \\
Women's schooling & 0.33 & \\
$\quad$ Did not attend primary school & 0.44 & 0.14 \\
Attended primary school or higher & & 0.20 \\
Development index & 0.22 & \\
2 & 0.33 & 0.11 \\
4 & 0.42 & 0.14 \\
6 & & 0.17 \\
Family planning facility & 0.33 & 0.14 \\
$\quad$ None inside the village & 0.33 & 0.22 \\
Inside the village & & \\
\hline
\end{tabular}

no more children is 0.33 . The corresponding probability for modern contraceptive use is 0.14 . This base scenario reflects the predicted value for a woman who is 31 years old, has no schooling, and has two or more sons. Monthly consumption per household member is set at 730 rupees and assumes that the husband resides with the family. There is no family planning facility inside the village, and the development index is 4 . There are two public boys' primary schools and one public girls' primary school in the village. The average amenities index for the boys' schools that the village children attend is 1.4, and the average amenities index for the girls' school that the village children attend is 1 .

Whether we consider all contraceptive use or only modern use, our models imply that a movement from no girls' school to two girls' schools in each community (which would roughly correspond to an equal number of girls' and boys' schools on average) would increase the probability of not wanting another child and using any contraceptive by $14-15$ percentage points. At the same time, shifting all women from never having attended school to ever having attended at least 
primary school would increase the probability of not wanting another child and using any contraceptive by 11 percentage points and the probability of not wanting another child and using a modern contraceptive by 6 percentage points, suggesting that one effect of education is to expand women's use of both modern and traditional methods.

An important and controversial comparison in the literature has been made between the influence of economic development on fertility (economic development is often thought to have an impact through its effect on fertility desires, which is clearly the case in our data set) and the influence of the availability of family planning facilities on fertility (see, for example, Bongaarts 1994 and Pritchett 1994). As mentioned before, we failed to detect an effect of the availability of a family planning facility on desired fertility, but we did find a statistically significant effect on modern contraceptive use for those women who expressed a desire to stop childbearing. Our estimates suggest that an upgrade of community infrastructure from a value of 2 on our development index ( 25 th percentile) to a value of 6 ( 75 th percentile) would lead to an increase of 20 percentage points in the use of any contraceptive method and an increase of 6 percentage points in the use of modern methods for this group of women. Again we can see the effect of improved communications and rising standards of living on the use of all types of contraceptives, not just modern methods. Indeed, we can see that while the presence of family planning facilities within the village can increase the level of modern contraceptive use by 8 percentage points, it has no effect on levels of use when all methods are included, as it is clear that traditional method use represents more than half of all use.

\section{CONCLUSIONS}

Opportunities for primary schooling in the community clearly play a role in influencing the fertility transition in rural Pakistan. In particular, gender equity in the schooling environment, as measured by the number of public primary 
schools for girls in the community (controlling for the number of boys' schools) or as measured by the ratio of the number of girls' schools to boys' schools, has a statistically significant effect on the probability that a woman will express a desire to stop childbearing and, by extension, on the probability that she will operationalize those desires by practicing contraception. Indeed, the achievement of gender equity in primary school access in rural Punjab and Northwest Frontier Province could lead to a 14-15 percentage point rise in contraceptive use in villages where no girls' public primary school currently exists and an 8 percentage point rise in villages with one primary school for girls. This is entirely supportive of Caldwell's argument that mass schooling is an important determinant of fertility change, particularly when educational opportunities are extended to girls as well as boys. It appears that fertility change will come about much more slowly when girls are left behind.

These findings have obvious policy implications for both the education and population sectors. For the education sector, the findings underscore the need to maintain equity in the supply of primary schools for boys and girls at the village level. While school quality may also be a factor, none of the measures of school quality that we experimented with were statistically significant determinants of fertility preferences. This may be either because we did not measure those features of school quality that parents find to be most salient or because school quality is a more important factor in explaining various types of school outcomes than in explaining women's fertility preferences.

For the population sector, this paper establishes that the presence of a family planning worker or a center can increase the use of modern methods but has little impact on overall levels of use, given the substitutability of traditional methods for modern methods. It is clear that couples will seek the means to control fertility whether or not a facility is available within their village and are as likely to rely on traditional methods as on modern ones. In particular, our findings point 
to the importance of the demand for fertility change being triggered through investment opportunities for schooling of boys and girls. This is the critical factor in catalyzing the demand for fertility limitation and for reproductive behavioral change.

Ultimately our findings are strong testimony to the necessity for gender equity in promoting social change in Pakistan. Glaring inequities in the education sector manifest themselves in a roughly 2 to 1 ratio of boys' public schools to girls' public schools. While the national Social Action Program was originally intended to redress some of these gender disparities, its emphasis may have been misplaced in chasing the target of increasing schools overall without due attention to bringing equity in the conditions and supply of girls' primary schools, village by village.

\section{Notes}

1 Fertility declines have been gentler than might be predicted by rising contraceptive use alone. This is thought to be attributable to a decline in the duration of breastfeeding.

2 Pakistan has no compulsory schooling law at the national level (Mahmood 1997), and the government makes no attempt to influence parents' decisions about their children's schooling through other means such as media campaigns or information, education, and communication strategies. However, in Punjab a Compulsory Education Act was promulgated in 1994.

3 SAP is a program of reforms in the education sector as well as in other areas such as health, family welfare, water, and sanitation (Federal Bureau of Statistics 1998).

4 In our sample, more than 80 percent of parents believe that both their boys and girls learn better in a single-sex environment in primary school (Sathar, Lloyd, and ul Haque 2000). 
5 Dynamic models clearly offer a better approximation of the decisionmaking process. The data requirements for estimable dynamic models are substantial, however. Influential papers on the topic include Wolpin (1984) and Montgomery (1993).

6 Axinn (1993) also explored the relationship between children's schooling and fertility in one village in Nepal. He found that parents' sending their oldest child to school had a statistically significant positive effect on parents' ever use of contraception and a statistically significant negative effect on their desire for more children. He found similar results for the proportion of children sent to school. Because the study was conducted in a single village, however, it cannot be viewed as a test of Caldwell's massschooling hypothesis. Furthermore, in light of the endogenous nature of fertility and schooling at the household level, problems are encountered in interpreting causality.

7 The proportion of 7-14-year-olds currently attending school was regressed on per capita household expenditure and a dummy variable for NWFP across the 55 rural districts of Punjab and NWFP. The coefficient on per capita expenditure was 3.6 per 1,000 rupees. School enrollment rates from the PIHS range from 17 percent to 93 percent in Punjab and from 16 percent to 88 percent in NWFP. For the three districts selected from Punjab, Sialkot had an enrollment rate of 81 percent (22 percentage points above what was predicted by the regression line), D.G. Khan had an enrollment rate of 52 percent (one percentage point below that predicted by the regression line), and R.Y. Khan had an enrollment rate of 41 percent (19 percentage points below what was predicted by the regression line). For the three districts selected from NWFP, Abbotabad had an enrollment rate of 77 percent (22 percentage points above the regression line), Karak had an enrollment rate of 54 
percent ( 3 percentage points below the regression line), and Swat had an enrollment rate of 44 percent ( 9 percentage points below the regression line). Our two PSUs from Swat had much higher enrollment rates than implied by the PIHS, so Swat turned out to be an area with much higher education than expected.

8 While several of these districts are well known internationally—such as Swat for its mountain scenery and several elite boarding schools, Abbotabad for its military academy, and Sialkot for the production of footballs-they were chosen entirely at random from the group of potentially eligible districts. The same is true of the individual communities chosen within the districts.

9 We acknowledge the assistance of Salman Zaidi in the development of the consumption module and training our field team in its application.

10 All primary schools in the village were visited as well as any outside the village that attracted at least 10 percent of the children from the village. Some children attended schools that we did not visit, but in these schools current attendance rarely exceeded 1-5 children.

11 Women who responded that they did not know whether or not they wanted to have more children were included with those who expressed a desire for spacing or a desire to have another child immediately.

12 Two of the 14 private schools were for boys only. There were no all-girls private schools in our sample.

13 Clearly, revealed fertility preferences of women are less capable of explaining contraceptive use behavior if husbands and wives do not share the 
same views. The question regarding fertility desires was asked of all currently married women and their husbands. Although only 61 percent of the husbands were interviewed successfully, we felt it was important to investigate whether or not it would be desirable to operate with a smaller (and not randomly selected) sample by taking into account both wives' and husbands' fertility desires. After eliminating the "undecided" cases, a crosstabulation of wives' and husbands' responses reveals that 81 percent of husbands of women who do not want additional children also do not want additional children. Eighty-five percent of husbands of women who want at least one more child also want at least one more child. While these percentages may not necessarily represent the entire sample, 82 percent of couples are in agreement in terms of their fertility preferences. This percentage is in line with the figures reported by Mason and Smith (2000) for Punjab (range, 76 percent to 88 percent). Thus, evidence suggests that a focus on women's fertility desires as a determinant of contraceptive use behavior would be an acceptable strategy in our case.

14 For a review of the literature on son preference and its effect on contraceptive use, see Clark (2000).

15 Using data from the International Food Policy Research Institute survey in rural Pakistan, Alderman et al. (1997), for example, argue that availability of schools in the community can be considered beyond the control of individual households. Because their analysis has this implication when district dummies are present in the model, we reran our regressions with province dummies, and the significance and magnitude of all variables in our models remained the same with the exception of the coefficient on the development index, which became insignificant. Because our survey collected data on only two villages from each district, it is not possible to 
investigate this issue at the district level. Note that the use of district dummies by Alderman et al. (1997) roughly corresponds to the use of province dummies, as their data contained one district from NWFP, two districts from Punjab, and one district from Sind.

16 For the estimation of the contraceptive use models (Table 5), we exclude from the sample women who cannot have children and pregnant women. In the models focusing on fertility desires only (Table 3), we exclude women who cannot have children, but we retain pregnant women (they are asked about their desire to have another child after the one currently expected). Overall, the data seem consistent, although we detected three cases in which women who revealed their preference to have another child as soon as possible were nevertheless using contraception. These cases might be explained either by the inability to immediately stop the effectiveness of certain kinds of contraceptives such as injectables, or by the contradictory fertility desires of the husband. These three cases were excluded from the analysis (the way these cases are treated does not affect the parameter estimates).

17 The Wald test statistic for the hypothesis that $\rho=0$ has a chi-squared distribution with 1 degree of freedom. The critical value from the chi-squared table at the 1 percent level is 6.63 , and thus the hypothesis that $\rho=0$ is decisively rejected in all models considered (see Table 5).

18 To see whether it is sensible to exclude the indicator of family planning facility availability from the selection equation, we experimented with estimating this equation with the family planning facility dummy (notice that probit estimation of the selection equation would not lead to biased parameter estimates). In this alternative specification, the coefficient estimate for the presence of a family planning facility is far from being statistically significant, is negligible in magnitude, and has a negative sign (not shown). 


\section{References}

Alderman, Harold et al. 1997. "The income gap in cognitive skills in rural Pakistan," Economic Development and Cultural Change 46(1): 97-121.

Axinn, William G. 1993. "The effects of children's schooling on fertility limitation," Population Studies 47(3): 481-493.

Axinn, William G. and Jennifer S. Barber. 1999. "Mass education and fertility transition," paper presented at the Annual Meeting of the Population Association of America, New York, 25-27 March.

Becker, Gary S. 1991. A Treatise on the Family. Second Edition. Cambridge, MA: Harvard University Press.

Becker, Gary S. and H. Gregg Lewis. 1973. "On the interaction between the quantity and quality of children," Journal of Political Economy 81(2): S279_ S288.

Bledsoe, Caroline H., John B. Casterline, Jennifer A. Johnson-Kuhn, and John G. Haaga (eds.). 1999. Critical Perspectives on Schooling and Fertility in the Developing World. Washington, DC: National Academy Press.

Bongaarts, John. 1994. "The impact of population policies: Comment," Population and Development Review 20(3): 616-620.

Caldwell, John C. 1980. "Mass education as a determinant of the timing of fertility decline," Population and Development Review 6(2): 225-255.

Casterline, John B. 1985. "Schooling and fertility: A multilevel approach," in Proceedings of the International Population Conference, vol. 2. Florence, Italy, 5-12 June, pp. 7-20.

1987. "The collection and analysis of community data," in John Cleland and Chris Scott (eds.), The World Fertility Survey: An Assessment. Oxford: Oxford University Press. 
Clark, Shelley. 2000. "Son preference and sex composition of children: Evidence from India," Demography 37(1): 95-108.

Cochrane, Susan H. and David K. Guilkey. 1995. "The effects of fertility intentions and access to services on contraceptive use in Tunisia," Economic Development and Cultural Change 43(4): 779-804.

DeGraff, Deborah S., Richard E. Bilsborrow, and David K. Guilkey. 1997. “Community-level determinants of contraceptive use in the Philippines: A structural analysis," Demography 34(3): 385-398.

Entwisle, Barbara et al. 1996. "Community and contraceptive choice in rural Thailand: A case study of Nang Rong," Demography 33(1): 1-11.

Federal Bureau of Statistics. 1997. Pakistan Integrated Household Survey, Round 2: 1996-97. Islamabad: Government of Pakistan.

1998. PIHS Education Sector Performance in the 1990s. Islamabad: Government of Pakistan.

Gardner, Robert. 1998. Education. Demographic and Health Surveys Comparative Study no. 29. Calverton, MD: Macro International.

Gertler, Paul J. and John W. Molyneaux. 1994. "How economic development and family planning programs combined to reduce Indonesian fertility," Demography 31(1): 33-63.

Guilkey, David K. and Susan Jayne. 1997. "Fertility transition in Zimbabwe: Determinants of contraceptive use and method choice," Population Studies 51(2): 173-189.

Hakim, Abdul, John Cleland, and Mansoor ul Hassan Bhatti. 1998. Pakistan Fertility and Family Planning Survey 1996-97, Preliminary Report. Islamabad: National Institute of Population Studies and London School of Hygiene and Tropical Medicine, Centre for Population Studies. 
Hakim, Abdul and Sarah Salway. 1999. "Women's autonomy and the uptake of contraception in Pakistan," paper presented at the Conference to Disseminate Results of Research on Reproductive Health, Islamabad, Pakistan, 14 April.

Heckman, James J. 1979. "Sample selection bias as a specification error," Econometrica 47(1): 153-162.

Khan, Shahrukh, Sajid Kazmi, and Zainab Latif. 1999. "The state of basic education in Pakistan: A qualitative comparative institutional analysis," Sustainable Development Policy Institute Working Paper no. 47. Islamabad: Sustainable Development Policy Institute.

Lam, David and Suzanne Duryea. 1999. "Effects of schooling on fertility, labor supply, and investments in children, with evidence from Brazil," Journal of Human Resources 34(1): 160-192.

Lloyd, Cynthia B., Carol E. Kaufman, and Paul Hewett. 2000. "The spread of primary schooling in sub-Saharan Africa: Implications for fertility change," Population and Development Review 26(3): 483-515.

Mahmood, Naushin. 1992. "The desire for additional children among Pakistani women: The determinants," Pakistan Development Review 31(1): 1-30.

- 1997. "Trends, issues and policies in education: A case study of Pakistan," unpublished manuscript. Islamabad: Institute of Development Economics.

Mason, Karen O. and Herbert L. Smith. 2000. 'Husbands' versus wives' fertility goals and use of contraception: The influence of gender context in five Asian countries," Demography 37(3): 299-311.

Montgomery, Mark R. 1993. "A dynamic model of contraceptive choice," unpublished manuscript. Princeton, NJ: Office of Population Research, Princeton University. 
Pritchett, Lant H. 1994. "Desired fertility and the impact of population policies," Population and Development Review 20(1): 1-55.

Sathar, Zeba A. and John B. Casterline. 1998. "The onset of fertility transition in Pakistan," Population and Development Review 24(4): 773-796.

Sathar, Zeba, Nigel Crook, Christine Callum, and Shahnaz Kazi. 1988. "Women's status and fertility change in Pakistan," Population and Development Review 14(3): 415-432.

Sathar, Zeba, Cynthia B. Lloyd, and Minhaj ul Haque. 2000. Investments in Children's Education and Family Building Behavior in Rural Pakistan: Lessons from NWFP and Punjab. Islamabad: Population Council.

Sathar, Zeba and Karen Mason. 1993. "How female education affects reproductive behavior in urban Pakistan," Asian and Pacific Population Forum 6(4): 93-103.

van de Ven, Wynand P.M.M. and Bernard M.S. van Praag. 1981. "The demand for deductibles in private health insurance: A probit model with sample selection," Journal of Econometrics 17: 229-252.

Wolpin, Kenneth I. 1984. "An estimable dynamic stochastic model of fertility and mortality," Journal of Political Economy 92(5): 852-874.

UNESCO. 1999. Statistical Yearbook. Paris: UNESCO. 


\title{
POLICY RESEARCH DIVISION WORKING PAPERS
}

\author{
Recent Back Issues
}

\section{8}

*106 Sajeda Amin and Gilda Sedgh, "Incentive schemes for school attendance in rural Bangladesh."

107 Martin Brockerhoff and Paul Hewett, "Ethnicity and child mortality in sub-Saharan Africa."

108 Ann E. Biddlecom and Bolaji M. Fapohunda, "Covert contraceptive use: Prevalence, motivations, and consequences."

109 John Bongaarts and Griffith Feeney, "On the quantum and tempo of fertility."

110 Barbara S. Mensch, Daniel Bagah, Wesley H. Clark, and Fred Binka, "The changing social environment for adolescents in the Kassena-Nankana District of northern Ghana: Implications for reproductive behavior."

111 Martin Brockerhoff and Ann Biddlecom, "Migration, sexual behavior, and HIV diffusion in Kenya."

112 Zeba A. Sathar and John B. Casterline, "The onset of fertility transition in Pakistan."
113 Geoffrey McNicoll, "Government and fertility in transitional and posttransitional societies."

*114 John Bongaarts, "Fertility and reproductive preferences in post-transitional societies."

115 Fiona Steele, Sajeda Amin, and Ruchira T. Naved, "The impact of an integrated micro-credit program on women's empowerment and fertility behavior in rural Bangladesh."

*116 Cynthia B. Lloyd, Barbara S. Mensch, and Wesley H. Clark, "The effects of primary-school quality on the educational participation and attainment of Kenyan girls and boys."

*117 Sajeda Amin and Cynthia B. Lloyd, "Women's lives and rapid fertility decline: Some lessons from Bangladesh and Egypt."

118 James F. Phillips and Mian Bazle Hossain, "The impact of family planning household service delivery on women's status in Bangladesh."

*119 Mark R. Montgomery and John B. Casterline, "Social networks and the diffusion of fertility control."

* No longer available 
*120 John Bongaarts, "The fertility impact of changes in the timing of childbearing in the developing world."

*121 James F. Phillips, Wendy L. Greene, and Elizabeth F. Jackson, "Lessons from community-based distribution of family planning in Africa."

122 Mark R. Montgomery, "Mortality decline and the demographic response: Toward a new agenda."

*123 Mark R. Montgomery, Mary ArendsKuenning, and Cem Mete, "The quantity-quality transition in Asia."

124 Barbara S. Mensch, Wesley H. Clark, Cynthia B. Lloyd, and Annabel S. Erulkar, "Premarital sex and school dropout in Kenya: Can schools make a difference?"

125 John Bongaarts and Rodolfo A. Bulatao, "Completing the demographic transition."

126 Geoffrey McNicoll, "Population weights in the international order."
127 Cynthia B. Lloyd, Carol E. Kaufman, and Paul Hewett, "The spread of primary schooling in sub-Saharan Africa: Implications for fertility change."

128 John B. Casterline, "The onset and pace of fertility transition: National patterns in the second half of the twentieth century."

129 Mark R. Montgomery, Michele Gragnolati, Kathleen Burke, and Edmundo Paredes, "Measuring living standards with proxy variables."

130 Bamikale Feyisetan and John B. Casterline, "Fertility preferences and contraceptive change in developing countries."

131 Martin Brockerhoff, "Urban growth in developing countries: A review of projections and predictions."

132 Omaima El-Gibaly, Barbara Ibrahim, Barbara S. Mensch, and Wesley H. Clark, "The decline of female circumcision in Egypt: Evidence and interpretation."

* No longer available 
133 Mary Arends-Kuenning and Sajeda Amin, "The effects of schooling incentive programs on household resource allocation in Bangladesh."

134 John Bongaarts and Charles F. Westoff, "The potential role of contraception in reducing abortion."

135 John B. Casterline and Steven W. Sinding, "Unmet need for family planning in developing countries and implications for population policy."

136 Carol E. Kaufman, Thea de Wet, and Jonathan Stadler, "Adolescent pregnancy and parenthood in South Africa."

137 Valerie L. Durrant and Zeba A. Sathar, "Greater investments in children through women's empowerment: A key to demographic change in Pakistan?"

138 Sajeda Amin, Alaka Malwade Basu, and Rob Stephenson, "Spatial variation in contraceptive use in Bangladesh: Looking beyond the borders."
139 Geoffrey McNicoll, "Managing population-environment systems: Problems of institutional design."

140 Barbara S. Mensch, Barbara L. Ibrahim, Susan M. Lee, and Omaima ElGibaly, "Socialization to gender roles and marriage among Egyptian adolescents."

141 John Bongaarts and Elof Johansson, "Future trends in contraception in the developing world: Prevalence and method mix."

142 Alaka Malwade Basu and Sajeda Amin, "Some preconditions for fertility decline in Bengal: History, language identity, and an openness to innovations."

143 Zeba Sathar, Cynthia B. Lloyd, Cem Mete, and Minhaj ul Haque, "Schooling opportunities for girls as a stimulus for fertility change in rural Pakistan." 